\title{
5. The mechanisms of media storms
}

\author{
Anne Hardy \\ Vasterman, Peter (ed.), From Media Hype to Twitter Storm. News Explo- \\ sions and Their Impact on Issues, Crises, and Public Opinion. Amsterdam \\ University Press, 2018 \\ DOI: $10.5117 / 9789462982178 / \mathrm{CHO} 5$
}

\begin{abstract}
This chapter investigates the underlying mechanisms of media storms. In other words, what happens exactly on the level of the news-making process when a storm breaks? From the literature, two complementary mechanisms are derived: lower gatekeeping thresholds and imitation. To illustrate these mechanisms, a qualitative dataset of sixteen semistructured interviews with senior editors and news managers is used. I find evidence for both mechanisms. Lowering thresholds do explain why media storms occur. Further, news outlets look at each other, imitation is daily routine. But the process of imitation is intensified by the presence of a media storm, especially between directly competing outlets.
\end{abstract}

Keywords: media storms, mechanisms, lowering thresholds, imitation

For 125 days, Salah Abdeslam, one of the ten men suspected of carrying out the attacks in Paris on 13 November 2015, was the most wanted man in Europe. He handled the logistics for the Paris attacks: he was the fixer, renting cars, finding apartments, picking people up and dropping them off. Abdeslam was supposed to die on 13 November, but instead fled to Brussels just hours after the attacks (Rubin, 2016). For 125 days, Belgian authorities failed to find him. After a four-month international manhunt, on the afternoon of 18 March 2016, Abdeslam was arrested in the Molenbeek neighbourhood of the Belgian capital.

On the morning of that day, a group of senior news editors of the commercial broadcaster VTM gathers for a team-building seminar. During lunch, a couple of hours before the arrest, they are notified that Salah Abdeslam is to be arrested. The group of editors decides to interrupt their seminar and to return, together, to the newsroom to cover the arrest in a live broadcast. On the other side of Brussels, the public channel VRT is also following the 
latest developments on the possible arrest. Forty-five minutes after VTM NEWS starts their live broadcast, VRT NEWS also interrupts their regular broadcasting schedule for an extra newscast. Both broadcasters devote extensive coverage to the latest developments.

Only a few days later, on 22 March, Brussels is startled by several bomb blasts at the national airport and at the Maalbeek subway station. At 8 am, the editorial news office of VTM NEWS hears that there has been an explosion at Brussels Airport. The senior editor of VTMNEWS says: 'It only took us four seconds to link the explosion to possible attacks. [...] And after eight seconds, you realize that this will be something heavy: a big disaster or an attack. Since Charlie Hebdo, we are in a permanent "it is possible that an attack will happen"-mode'.

What follows in the hours after the first explosion at Brussels Airport is unprecedented. Both broadcasters VRT NEWS and VTM NEWS go live for fourteen hours straight to bring the latest updates on the attacks. Even journalists who are not supposed to be working that day come to the news office to help. Nearly everyone is reassigned to cover the bombings. Newspapers also staff their online offices with extra personnel. The newsrooms stay in 'storm mode' for many days. Not just on the day of the bombings, but also during the days afterwards, media outlets generate multiple news updates and follow-up stories about the bombings.

The Brussels bombings that took place on 22 March 2016 are an example of a media storm: an explosive and high-level surge in attention surrounding a triggering event that dominates news coverage for weeks. Most people are able to recognize a media storm when they see one. When media consumers cannot avoid an issue wherever they look, a media storm occurs. Several scholars have tried to define this phenomenon of suddenly peaking media attention in various ways. Vasterman (2005) was one of the first scholars explicitly addressing the similar concept of a media hype. He defines a media hype as 'a media generated, wall-to-wall news wave triggered by one specific event and enlarged by a self-reinforcing process within the news production of the media' (Vasterman, 2005, p. 515). Wien and ElmelundPræstekær (2009) draw upon this definition, but argue that the distinction between news 'making' and news 'reporting' is hard to make in practice. Therefore, they opt to consider media hypes simply as instances of very intense media coverage on a single issue (Wien \& Elmelund-Præstekær, 2009, p. 185). Wolfsfeld and Shaefer (2006) speak of political waves as sudden and significant changes in the political environment, characterized by a substantial increase in the amount of public attention - measured and driven by media attention - centred on a political issue or event. Most 
previous work studies one single case: Vasterman (2005) investigates events of random violence in the Netherlands and Wien and Elmelund-Præstekær (2009) look at scandals about care of the elderly in Denmark. These studies do not investigate whether the storms they identify are generic phenomena applicable to other issues and other systems. Together with Amber Boydstun and Stefaan Walgrave (2014, p. 511) I argue that a more generic concept is needed. Elaborating on previous work, they introduce the concept of a media storm and identify three crucial characteristics - size, duration and explosiveness - which they incorporate in their definition of a media storm: 'an explosive increase in news coverage to a specific issue constituting a substantial share of the total news agenda devoted to the issue during a certain time'. They also use these three criteria to develop an operationalization for systematically gauging media storms. The current chapter builds on this latter conceptualization.

The example of the Brussels bombings illustrates what happens when a media storm breaks. Media outlets are taking decisions to deliver extra newscasts influenced by the decision their competitors take. Moreover, in such situations, media outlets are covering the story extensively and produce many more news items than they normally do. Previous work has already speculated about the drivers of media storms, but no study has yet investigated it in a systematic and empirical way. The aim of this chapter is to find out how media storms come about and to see how this process differs from non-storm coverage ('a routine day'). In other words, what are the mechanisms of media storms? A, are the mechanisms of media storms different from mechanisms for 'non-storm/routine' coverage?

\section{Illustrating the mechanisms of media storms}

Investigating what drives media storms contributes to a recent and growing body of work dealing with media dynamics. Previous work has already speculated on the drivers of media storms, but no study has yet investigated it in a systematic and empirical way. Boydstun et al. (2014, p. 512) have distinguished two possible mechanisms. First, Kepplinger and Habermeier (1995) identify a change of selection criteria after a key event happens. Specifically, they mean that a key event triggers an increase in coverage of that event, and of similar and thematically related events. Wolfsfeld and Shaefer (2006, p. 336) make a similar argument: 'Once a wave materializes, media will link events with the overall story and search for sources, information, events'. Events that in different circumstances would not have 
been salient enough to make it into the news do now pass the media gates and get coverage. This first mechanism explains why media storms are not one-day phenomena, but instead go on for, at least, a few days.

The first mechanism mentioned above refers to an intra-medium phenomenon: a single news outlet can increase its coverage, irrespective of what other media are doing, as it temporarily implies less strict criteria for newsworthiness. The second is a multimedia one: news outlets imitate one another's news coverage. Scholars have often referred to such self-referential processes, disconnected from the outside world, leading to pressure on every news desk to join the pack (Kitzinger \& Reilly, 1997; Vasterman, 2005). Combined, these emulating micro-decisions may lead to a storm on the aggregate level. The second media-storm-generating process especially affects the explosiveness of a storm: imitation on a large scale leads to quickly peaking media attention. Media storms happen because different media simultaneously pick up a news item, which creates a collective dynamic of increasing coverage. In what is truly a self-reinforcing process, this collective dynamic further fuels individual news outlets' incentives to stay locked on the storm.

The theory has probably not been tested so far because it is quite complex to really disentangle these mechanisms in a quantitative way. It requires very detailed data on the micro-level, such as hourly news updates from news websites, which is a very time-intensive process. For this reason, I chose for a qualitative approach. I have used interviews to extract the data needed to disentangle these mechanisms. The benefits of using a qualitative approach are demonstrated here, because they bypass some of the problems mentioned above while delivering insightful evidence. It is important to note that this approach will not really test the mechanisms of media storms, but rather illustrate them based on the perception of journalists. This chapter explains how journalists experience a media storm and what they think happens during a storm. Journalists, especially chief/ senior editors and news managers, are valid sources, since they possess the expertise, authority, and responsibility to decide. They know what a media storm is from hands-on experience, rather than from study.

Two series of interviews were conducted. In the first round, in the summer of 2013, I held nine semi-structured interviews with general editors of newspapers and newscasts of the public broadcaster VRT and the commercial broadcaster VTM. At the beginning of each interview, I sketched my research design and explained how I conceptualized and measured media storms. This was to avoid a situation where editors might talk intuitively about big disasters only, such as the Sierre crash. ${ }^{1}$ Of course, people always refer to 
what is at the front of their minds. In the summer of 2013, the accession to the throne of King Filip took place. Many interviewees referred to this example because it was a big event that summer. After the Brussels bombings in 2016, a second round of semi-structured, telephone interviews was conducted. For these interviews, I looked for journalists who operate in the newsroom. Whereas most general editors mainly deal with the general policy of their news service, news managers and senior editors actually create the news. No general questions about media storms were asked this time. I briefly introduced the topic to the interviewees, and the questions explicitly dealt with the Brussels bombings. The journalists were, for example, asked to describe exactly what happened in the newsroom on the day of the bombings.

\section{Just an ordinary news day}

To understand what happens exactly when media outlets go into storm mode, it is useful to illustrate first how news is made on an 'ordinary', routine news day. In other words, which procedures are used on a daily basis? After doing this, I will shed light on the motivations behind these ordinary news decisions. More specifically, I will look at imitation as a motivation for certain news decisions.

\section{News procedures: How news is made}

Journalists depend on a set of routines to do their job (Boydstun, 2013; Gans, 1979; Iyengar \& McGrady, 2007). The purpose of these routines is to deliver, within limited time and space, the most acceptable product, in the most efficient manner, to the consumer (Shoemaker \& Reese, 1991). All media outlets work with a fixed format. The particular events that occur change daily, but the process of news-making does not. In most newspapers' newsrooms, the senior editor starts the day with a 'news watch'. He or she gets information about events that happened during the night, makes a summary of the interesting news items in other newspapers (also in Walloon and foreign newspapers), reads his or her own newspaper again and listens to the radio to hear what the radio news picked up from the newspapers. Then, there is a morning meeting led by the general editor or news manager. Here, the 'news watch' is presented and journalists can present their new ideas. Those attending the meeting depends on the newspaper, with only the head of departments present at De Standaard and De Morgen, and any journalist from the publication invited at Het Laatste Nieuws. At Het Nieuwsblad, 
journalists can choose whether or not to come to the morning meeting, but if they come, they should introduce an idea. After this meeting, the process of news-making can start. At De Standaard, for example, the head of each department has another meeting with their individual team(s), while Het Laatste Nieuws and Het Nieuwsblad opt for more centralization; all news selection decisions are made by the chief editor. So, at some newspapers decision-making is more centralized than at others.

For television, a similar process takes place. A selection is made based on what journalists read in the newspapers, what radio news has already taken from the newspapers, and the news calendar. This calendar bundles all scheduled events and media outlets - especially TV - anticipate it keenly. A weekly/daily plan is made that appoints specific journalists and camera crews in advance to specific events and news items. The ipm newscast serves as a framework for the rest of the day. After this, the newscasts of both VRT and VTM evaluate both their own and each other's newscasts and make only a few adjustments for subsequent newscasts.

\section{Motivations behind news decisions: Imitation}

News outlets thus follow a twenty-four-hour news cycle. Imitation is key in their daily routine: every morning, news editors read the newspapers of their competitors. Radio news uses the newspapers as the starting point of their daily news selection; consequently, television takes over the most important facts of the newspapers and the radio news. A study on intermedia agenda-setting in Flanders has shown that radio is a key player. Radio news - more specifically De Ochtend, a daily news show on Radio 1 , which is broadcast from 6 am to gam - selects the news of the day from the newspapers and sets the agenda for television news later on that day (Hardy, 2008). Liesbeth Van Impe (Het Nieuwsblad) indicates that this can be frustrating for newspapers: 'You often wonder', she says, 'why do media outlets take over that particular news fact?!

Scholars of inter-media agenda-setting have shown that directly competing outlets in particular take notice of each other's news selection decisions and tend to embrace issues that the competition has covered before (e.g. Boyle, 2001; Vliegenthart \& Walgrave, 2008). This is illustrated by Dimitri Antonissen of Het Laatste Nieuws, who, when describing the start of his working day, said that 'one of the very first things I do in the morning is skim very fast our main competitor's newspaper Het Nieuwsblad'. News editors constantly want to know if they have missed something. Steven De Bock of Het Nieuwsblad also confirms this: 'Of course we look at our competitors. 
We assess our newspaper based on what our competitors have shown us. It's not possible to make a good newspaper if theirs is better'. Yves Desmet (De Morgen) adds: 'We look at our peers. For example, what was the first item of the VRT newscast? If VRT NEWS starts with this story, then it is by definition important, isn't it?'

Imitation is thus a daily routine for journalists. Liesbeth Van Impe of Het Nieuwsblad explains: 'Media look at each other constantly. It is a kind of reflex. In this way, news gets defined. If two newspapers cover the same issue then it is per definition newsworthy and other outlets will cover it as well'. Wim Willems (VRT NEWS) adds:

Media influence each other. Newspapers influence television and radio and vice versa. VTM influences VRT and VRT VTM. As a news editor you have to read newspapers and listen to the radio to know what the competitors are doing. If other news outlets are bringing a story that you haven't covered yet, you immediately think 'why haven't we covered this yet?' and start thinking about which aspect is not covered yet to elaborate on the story. This only has advantages for the media consumer. Media are incentivized to perform as well as possible.

\section{What a difference a day makes: Media storm}

In the previous section, I looked at an 'ordinary' news day. In this section, I try to systematically compare non-storm news coverage with media storms coverage.

\section{Lowering news thresholds}

Let us go back to the moment when, on 22 March 2016, the first bomb exploded in Brussels airport, and reconstruct how this explosion changed the entire news production process on that day (and the days afterwards). Griet De Craen (VRTNEWS) described what staff at VRTNEWS did when the first information about the bombings came in: 'We immediately started by calling the police, the airport [...] to verify if our information is correct and what's going on [...]. After only a few minutes, we knew that this was really serious'. What follows is a significant organizational change; the newsroom is operating in a different mode: storm mode. Concretely, (1) coordination becomes extremely important, and (2) nearly all journalists are re-assigned to cover the story of the day. 
When a storm breaks, coordination is extremely important. Due to the fact that in storm mode decisions are now mostly made top-down, there is less room for individual journalists to come up with ideas about other issues/events that they want to cover. The chief editor and news managers have to clarify decisions about how the event will be covered and about the division of labour. Griet De Craen (VRT NEWS) explains: 'On the day of the Brussels bombings, we had an hourly meeting with general editors and senior editors of the different outlets (radio, website, TV)'. Emmanuel Rottey (Chief Editor Social Media VRT NEWS) adds: 'At that moment, it is important to coordinate between different channels and between different outlets. You have to make sure radio and television do not call the same people twice and that Het Journaal and TerZake cooperate on how they are going to cover the event'. The newspapers Het Laatste Nieuws and Het Nieuwsblad, for example, both normally working 'bottom-up' with an editorial meeting with all journalists, cancelled this meeting the day of the Brussels attacks. Peter Goris (Gazetvan Antwerpen) is more nuanced; he confirms that news managers take editorial decisions, but that all journalists can come up with ideas, even on very busy news days, such as the day the Brussels bombings happened.

In storm mode, almost all journalists cover the same issue, as Dimitri Antonissen (Het Laatste Nieuws) describes: 'When a storm breaks, the newsroom is divided in two teams. One news manager gathers a big team and they deal with the storm, the other news manager and a couple of other journalists take care of the rest of the news'. Peter Goris (Gazet van Antwerpen) explains that on the day of the Brussels bombings they worked with a team of three news managers instead of one: 'We have a rotating system with three news managers that alternately are responsible for the newspaper. When something really big happens, all three of us work. One news manager is coordinating the logistical stuff, the other one the journalists and the third one all the other news'.

Specialists on the topic are important, but so-called generalists are also asked to report on the issue. All interviewees indicated that on the day of the Brussels bombings all journalists - even those who were not supposed to work that day - were mobilized. Yves Desmet (De Morgen) confirms that this is true at all levels of expertise: 'On one hand, the specialist on a skiing holiday is told to put his Glühwein aside and come up with a hundred lines in print; on the other hand, people who know bugger all about the topic are told to make some phone calls. This way, the newsroom is a mixture of generalists and specialists'. Wim Willems (VRT NEWS) adds: 'A bunch of journalists will work on the same issue; also non-specialists. For example, 
Peter Verlinden, the Africa expert of the VRTNEWS, covered the succession of the throne in the summer of 2013. A lot of people were on vacation and we needed a big group of journalists to cover the event'. Antonissen (Het Laatste Nieuws) describes how this played out for the Brussels bombings: 'The decision to cover only the terrorist attacks was taken quite rapidly. The people working on other projects were re-assigned to the bombings. Even the people of NINA.be, our website for women, were brought in to cover the story'.

As a result of these organizational changes (more centralized coordination and reassignment of journalists), the newsroom will be super-focused on just one thing: covering the issue of the storm. When the entire newsroom is working on just one story, this simply leads to a bulk of news items about that story. The story is everywhere. The fact that the news organization is working top-down also contributes to this. The coordinating news manager has a clear task, organizing all input and output about the story. The simple fact that someone is managing the story leads to more news, follow-up stories, and stories with different angles. Even events that, in other circumstances, would not have been salient enough to make it into the news, now pass the media gates and get covered. This is called 'lowering thresholds': the media lower gatekeeping thresholds for similar later events and for 'after'-events (Brosius \& Eps, 1995; Kepplinger \& Habermeier, 1995). The logic of lowering news thresholds goes back to the 'continuity effect', already identified by Galtung and Ruge (1965, p. 82), who state that 'once an event has "made it" the news channel will be more readily open for the follow-up events, at a lower threshold value'. After an initiating event, journalists even start to cover similar past events that occurred before the key event took place. Journalists and editors know that such events can elicit high levels of public attention, leading to a demand for more information. Mass media try to satisfy this hunger by providing more news about the same issue.

If multiple significant events occur about the same topic, news outlets are more likely to go into storm mode. Jo Buggenhout of VTM NEWS explains: 'Since the beginning of last year, since Charlie Hebdo, we're in a kind of "attack modus"'. This means that terrorist events occurring in the weeks or months after Charlie Hebdo were heavily reported upon. Downs (1972) explains this using the 'issue attention cycle argument'. 'Once an issue has forcefully caught the attention of the media', says Downs, 'it stays there for a while until, inevitably, it fades away again as journalists start looking for other, fresh news'. The key element in Downs' account is that spectacularly heightened news attention for an issue is temporary. The public and the media will get bored and turn away. As long as the public stays tuned, the 
media will keep on covering the storm issue. Added to that, if news events connected to the media storm issue continue to unfold, journalists will continue covering them (and the threshold for covering events linked to the storm will remain low). In this sense, the duration of a storm probably critically depends on how political or other relevant actors deal with it. If elites keep talking and especially disagreeing about the issue and keep producing events that are worth covering, the storm continues.

\section{Imitation}

In this paragraph, I develop the argument that when a storm breaks, it is important to react quickly. Because news editors have to react fast, this leads to uncertainty. News editors are uncertain about how much attention they must devote to an event and find it hard to estimate what their main competitors will do. This causes imitation.

When a media storm occurs, it is important that news managers immediately undertake action. They make phone calls to inform other journalists and to gather extra information. Often an ad hoc 'news cell' is established. This team meets as soon as possible to see what and how the event is going to be covered, as Yves Desmet (De Morgen) describes: 'We put everything we've collected for tomorrow's newspaper with the garbage and start all over again. We immediately meet with all the specialists of that issue and ask ourselves: "these are the facts [...] what shall we do? What can we add to the story? What do we want to accomplish?"'

Procedures are more rigid for television news than for newspapers. Wim Willems (VRT NEWS) explains that they have a protocol when something big happens: "It is important to make fast decisions about an extra newscast. If we decide that the event can be categorized as "a big bang", all relevant actors simply have to open a script on their computer with a step-by-step plan about who needs to be contacted (for example, to interrupt the "regular" broadcasting schedule of broadcaster, to order extra camera crews)'. Newspapers have to decide if they produce an extra edition or extra pages. The website is also important, as Steven De Bock (Het Nieuwblad) confirms: 'We have to work at two different paces. The newspaper for the next day is important, but the website as well. On the day of the Brussels bombings, I immediately reassigned some journalists for the "paper version" of the newspaper to produce articles for the website'.

Technology has influenced the speed of news-making. Newspapers are now able to produce an extra edition, because it is technically possible to do this within a limited time frame. TV stations do not need a satellite wagon 
to go live, but instead use a 'WNT system' that works with $4 \mathrm{G}$. This gives a broadcaster the flexibility and mobility to cover the event faster.

All interviewees indicated that it is important for things to happen fast. Sometimes this leads to uncertainty. It is not always easy to make a correct estimation on how 'big' to make a particular story. At these moments, news outlets look to each other. What is the assessment of our main competitor? Has VTM made an extra newscast? Looking back at 18 March 2016, the day that Salah Abdeslam was arrested, a VRT NEWS journalist argues: 'We were in doubt whether we had enough information to bring an extra newscast [...] At such moments, you really look at the others'. Stories that are reported in different media at the same time create a collective dynamic of increasing coverage. Scholars have often referred to such self-referential processes, disconnected from the outside world, leading to pressure on every news desk to join the pack (Kitzinger \& Reilly, 1997; Vasterman, 2005). Together, these emulating micro-decisions may lead to a storm on the aggregate level. This second media-storm-generating process especially affects the explosiveness of a storm: imitation on a large scale leads to quickly peaking media attention.

Whereas lowering news thresholds causes media storms, imitation is responsible for sustaining them. Most news editors believe that imitation feeds the storm and makes them stronger. Dimitri Antonissen (Het Laatste Nieuws) and Wim Willems (VRTNEWS) attribute this to the increased level of competition. Antonissen: 'News editors ask themselves at the end of a big news day who was the best and who had the most viewers/readers'. Willems adds: 'The competition is brought to a higher level. We will look more closely what is in the newspapers and what they exactly write about. This might give us ideas how to cover the news ourselves'. Kris Hoflack (VTM NEWS) adds: 'Media reinforce each other during a storm. You know that if you decide to take over a news fact, it only gets bigger. In this way, you end in an irreversible news flow where you cannot step out anymore'. Tim Pauwels (VRT NEWS) argues that a news editor is restrained by fear:

The only thing a news editor asks himself at the end of the day is "have I missed something?" These people are constantly asked: why does competitor A or B cover this or that and we don't? It really takes a lot of courage to step out of the box. And it will only be done when the news editor feels sure that the mainstream choices are more or less covered. Given the shrinking resources of many redactions, at the end of the day, for many news outlets, the mainstream choices are all they end up doing. 
Desmet (De Morgen) explains his view: 'It's two-fold. For certain issues, you can see that we all go simultaneously in the same direction. But at other moments, you see that, call it a self-regulation mechanism, we don't because we make another estimation of the story or we do not begrudge our competitor to follow him'.

Let us illustrate this imitation process with an example. The first round of interviews took place in August 2013, only a few weeks after the accession to the throne of King Filip on 21 July. Most news editors indicate that they covered it extensively because they knew other media would do the same. Dimitri Antonissen (Het Laatste Nieuws): 'Yes, we gave a lot of attention to the abdication of King Albert; it was a big historical event and, more importantly, we didn't want to do less than the others, although we knew that probably a significant part of our readers didn't care about it'. Liesbeth Van Impe (Het Nieuwsblad) adds: 'I really was in doubt on how to cover it. Maybe our readers wouldn't mind if we'd brought only four pages. But as a news editor you make the consideration: every outlet is going to get big, so let's do it too'. This is an excellent example of a media storm that is initiated by a forecasted event. Outlets anticipate this event and they all cover it extensively because they expect the others to do so as well. In other words, anticipated imitation also often leads to explosive attention, triggering a media storm.

Yet, imitation does not always drive media storms. News managers were asked whether they closely watched their competitors on the day of the Brussels bombings. Most interviewees indicated that imitation did not play a role on this occasion. The reason is that the event was so obviously important that it was clear for each outlet that they had to cover it extensively. Jo Buggenhout (VTM NEWS) confirms that, under these circumstances, there is no need to look at others because 'you're just so focused on your own news'. Peter Goris (Gazet van Antwerpen) adds: 'Honestly, imitation did not play a role. Well, of course, you're in the flow. You look at the planning of De Standaard, Het Nieuwsblad, Het Belang van Limburg [all of these newspapers are in the same media group] and you know that they all focus on one thing. So, automatically, you go with them. But on the other side, this is just so evident'.

In sum, it seems that some level of imitation is a daily practice during routine periods. A majority of the interviewees indicated that imitation increases during a media storm compared to imitation during a 'routine day'. In other words, imitation is driving media storms. Imitation especially takes place when news editors are unsure about making a correct estimation of "how big" to make a story and how much attention they should pay 


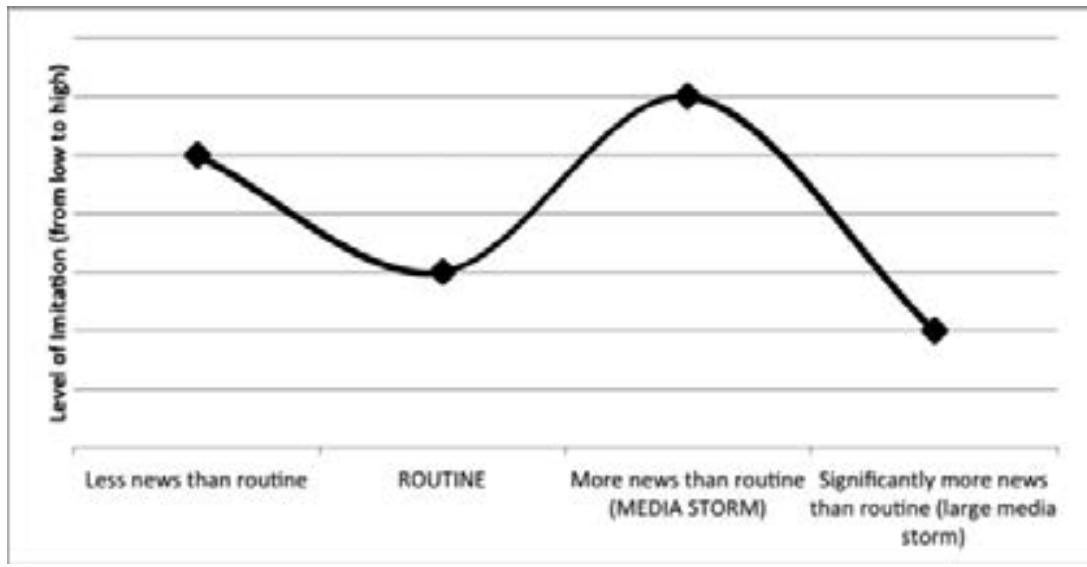

Figure 5.1. Level of imitation during (non) routine periods

to the topic. In a race against time, news editors are supposed to make fast decisions. At such a moment, media outlets will look to each other, and in particular to their direct competitors.

Figure 5.1 visualizes the level of imitation during routine and media storm periods, albeit appears somehow arbitrary to draw a line to indicate this. Based on the interviews, it is safe to say that imitation goes up during a media storm period (but also on a routine day there will always be some level of imitation). Two comments need to be formulated at the extreme left and extreme right side of the graph. On one hand, I learned during the interviews that imitation also takes place on a very slow news day, when there is nothing interesting to report on. Antonissen (Het Laatste Nieuws) explains: 'I think the slower the news day, the more competition. If you have sufficient own "exciting" material, you look less at your competitors. But at the moment you think "we don't have enough good stories for our newspaper" you will look at others more easily'. On the other hand, imitation becomes less important when the event is exceptionally large (e.g. the Brussels bombings) and a correspondingly large media storm breaks, as things are so obvious (and there is so much to be done on the news floor) that imitation becomes less important.

\section{Conclusion and discussion}

The main aim of this chapter was to illustrate the mechanisms of media storms and to systematically compare them with non-storm coverage. 
Previous literature has already identified two mechanisms at play: (1) lowering news thresholds (as a result of a spectacular event or development, news outlets temporarily change their news selection process and lower the thresholds of newsworthiness for similar issues and events); and (2) imitation: once a storm breaks, news outlets imitate one another's news selection decisions.

I believe I have found clear-cut evidence for the first mechanism. When a storm breaks, virtually the whole newsroom will be reassigned to the news story. Specialists will be asked to cover the core story; generalists cover similar events and follow-up stories. The newsroom is more centrally coordinated. The news manager assigned has one clear task: coordinating the complete story. He or she is responsible for ensuring that all angles are elaborated, all sources are interviewed and all follow-up stories are covered. Because of the coordination involved, it becomes an intensively reported story. The story will be high on the agenda, not only on the day it breaks, but also in the days following. A sensitivity for the issue is created for a certain period. Lowering thresholds explains why media storms take a large share of the agenda for multiple days.

Secondly, regarding imitation, the picture is a little less clear. Imitation is daily practice, but increases when a media storm takes place. Imitation explains why media storms are sustained. News editors confirm this. Media outlets look to each other due to the difficulties experienced by editors in estimating how intensively they should report on a story. But it appears that there is no linear relationship between the size of a story and the level of imitation. If the event is exceptionally big, journalists are focused solely on their own outlet and do not imitate others. In the case of the Brussels bombings, journalists were clear about the amount of news required and so put all of their efforts into covering this hugely important story. So, especially in the case of uncertainty, media outlets will look more closely at each other and imitation is more likely to occur.

This is the first study that aims to systematically investigate the mechanisms of media storms, hence this importance of using a qualitative approach. Interviews allowed me to explore the processes that cause media storms. Without doubt, this approach has advantages in this context. Had I conducted a quantitative analysis to investigate, for example, the level of imitation for storms versus non-storms, I would never have discovered the fluctuations in the level of imitation, because exceptionally big stories also count as media storms and really slow news days are part of the nonstorm coverage. My qualitative approach also allowed me to disentangle the process more precisely, something that is much more difficult with a 
quantitative approach. Of course, this approach also holds some limitations. It is difficult to claim that lowering news thresholds and imitations are the main mechanism of media storms; rather, I have illustrated how they play a role in the perception of journalists, news managers, and chief editors.

These findings provide a framework for further research about the topic. First, it would be interesting to set up a big project and test the mechanisms in a quantitative way. To what extent is the lowering threshold mechanism or the emulating inter-media mechanism responsible for provoking media storms? To measure this question, a micro-level dataset is required, of ews items on an hourly level, or even for a shorter time interval. Only then will it be possible to exactly disentangle the mechanisms. Second, this study is a single country study, which is an important limitation. A comparative design would be a very interesting path for further research. It might be that the mechanisms work differently in countries with a different media system to Belgium, for example countries that are more market-driven, such as the United States or Great Britain (Hallin \& Mancini, 2004). Finally, not only the investigation of mechanisms of media storms deserves more attention. Future research might explore the possible effects of media storms. Whereas previous research finds that the political agenda-setting power of the mass media is generally limited, it seems as though media storms could be a consequential phenomenon with the potential to demand reaction from political actors.

\section{Notes}

1. On 13 March 2013, a Belgian coach crashed into a wall in Switzerland. Of the fifty-two people on board, twenty-eight did not survive the accident.

\section{References}

Boydstun, Amber E. (2013). Making the news: Politics, the media, and agenda setting. Chicago, IL: University of Chicago Press.

Boydstun, Amber E., Hardy, Anne \& Stefaan Walgrave (2014). 'Two faces of media attention: Media storm vs non-storm Coverage'. Political Communication, 31(4): 509-531.

Boyle, Thomas P. (2001). 'Intermedia agenda-setting in the 1996 presidential election'. Journalism and Mass Communication Quarterly, 78 (1): 26-44. 
Brosius, Hans-Bernd \& Peter Eps (1995). 'Prototyping through key events: News selection in the case of violence against aliens and asylum seekers in Germany, European Journal of Communication, 10 (3): 391-412.

Galtung, Johan \& Mari Ruge (1965). 'The structure of foreign news'.Journal of Peace Research, 2: 64-91.

Gans, Herbert J. (1979). Deciding what's news: A study of CBS evening news, NBC nightlynews, Newsweek, and Time: Evanston, IL: Northwestern University Press.

Hallin, Daniel \& Paolo Mancini (2004). Comparing media systems. Three models of media and politics. New York: Cambridge University Press.

Iyengar, Shanto \& Jennifer A. McGrady (2007). Media politics: A citizen's guide. New York: W.W. Norton.

Kepplinger, Hans Mathias \& Johanna Habermeier (1995). 'The impact of key events on the presentation of reality'. European Journal of Communication, 10 (3): 371-390.

Kitzinger, Jenny \& Jacquie Reilly (1997). 'The rise and fall of risk reporting: Media coverage of human genetics research, 'false memory syndrome' and 'mad cow disease'. European Journal of Communication, 12 (3), 319-350.

Rubin, Alissa A. (2016). 'The arrest of Salah Abdeslam, a Paris suspect, ends manhunt, not questions'. The New York Times. 21 March 2016

Shoemaker, Pamela J. \& Stephen D. Reese (1991). Mediating the message. Theories of influences on mass media content. New York: Longman.

Vasterman, Peter (2005). 'Media-hype. Self-reinforcing news waves, journalistic standards and the construction of social problems'. European Journal of Communication, 20 (4): 508-530.

Vliegenthart, Rens \&Stefaan Walgrave (2008). 'The contingency of intermedia agenda-setting. A longitudinal study in Belgium'. Journalism and Mass Communication Quarterly, 85 (4): 860-877.

Wolfsfeld, Gadi \& Tamir Sheafer (2006). 'Competing actors and the construction of political news: The contest over waves in Israel'. Political Communication, 23 (3): $333-354$.

\section{About the author}

Anne Hardy is a member of the research group Media, Movements \& Politics at the University of Antwerp. She holds a PhD in political science. In her thesis she tackled the conducive factors, mechanisms and political effects of media storms. 